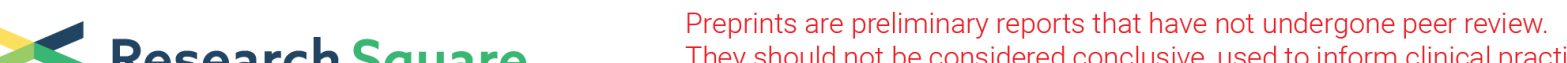 $\begin{array}{ll}\text { Research Square } & \text { They should not be considered conclusive, used to inform clinical practice, } \\ \text { or referenced by the media as validated information. }\end{array}$
}

\section{Environmental Exposure to Cooking Oil Fume and Fatty Liver Disease}

\section{Shun Zhang ( $\square$ zhang.s1@hotmail.com )}

Department of Experimental Medical Science, HwaMei Hospital, University of Chinese Academy of Sciences \& Key Laboratory of Diagnosis and Treament of Digestive System Tumors of Zhejiang Province Jie Lin

HwaMei Hospital, University of Chinese Academy of Sciences

\section{Saili Ni}

HwaMei Hospital, University of Chinese Academy of Sciences

\section{Qili Shi}

HwaMei Hospital, University of Chinese Academy of Sciences

\section{Zi Xiong}

HwaMei Hospital, University of Chinese Academy of Sciences

\section{Junfei Kang}

HwaMei Hospital, University of Chinese Academy of Sciences

\section{Xiaohua Sun}

HwaMei Hospital, University of ChineseAcademy of Sciences

\section{Yumeng Gao}

Chinese Academy of Medical Sciences \& Peking Union Medical College Hospital of Skin Diseases and Institute of Dermatology

\section{Huijing Zhang}

HwaMei Hospital, University of Chinese Academy of Sciences

\section{Shanyi Liu}

Chinese Academy of Medical Sciences \& Peking Union Medical College Hospital of Skin Diseases and Institute of Dermatology

\section{Ting Cai}

HwaMei Hopital, University of Chinese Academy f Sciences

\section{Research article}

Keywords: cooking oil fume, fatty liver, gender

Posted Date: May 15th, 2020

DOI: https://doi.org/10.21203/rs.3.rs-27864/v1 
License: (c) (i) This work is licensed under a Creative Commons Attribution 4.0 International License. Read Full License 


\section{Abstract}

Background: Evidence on effect of cooking oil fume, which contains numerous carcinogens, on development of fatty liver disease is limited. The present study aims to investigate the association between exposure to cooking oil fume and the risk of fatty liver disease.

Method: A total of 55959 participants aged between 40 and 75 years old participated in a communitybased survey in Ningbo, China. Information on exposure to cooking oil fume and fatty liver disease were collected by face-to-face interview. Stratified analysis was used with participants being divided into two groups according to gender. Multiple logistic regression analyses were conducted to investigate the association between cooking oil fume exposure and fatty liver risk. Furthermore, ordered logistic regression was conducted to investigate the association between cooking oil fume exposure and the severity of fatty liver disease.

Results: Fatty liver disease prevalence was $8.79 \%$ in none oil fume exposure group, $10.52 \%$ in light oil fume exposure group, $23.47 \%$ in moderate oil fume exposure group and $41.45 \%$ in heavy oil fume exposure group. After adjusting for confounding factors, participants in the light, moderate and heavy cooking oil fume exposure groups all had significantly higher odds ratios as compared with participants in the none oil fume exposure group. In addition, an interaction effect between cooking oil fume exposure and gender on the prevalence and severity of fatty liver disease was observed. Females with heavyoil fume exposure had the highest odds ratios of fatty liver disease and severer disease extent. In the stratified analysis, compared to participants in the smokeless group, males and females in light, moderate and heavy cooking oil fume exposure groups all had significantly higher risk of fatty liver disease and severer disease extent, while participants with heavier cooking oil fume exposure tended to have higher risk of fatty liver disease and severer disease extent.

Conclusion: Exposure to cooking oil fume is associated with incident and severity of fatty liver disease in 40-75 years old Chinese. The associations might be dose-responsive. In addition, heavy oil fume exposure and female sex might have a synergistic effecton incident and severity of fatty liver disease.

\section{Background}

Fatty liver disease is characterized by fat deposits in liver cells and encompasses a broad array of liver pathology, ranging from asymptomatic steatosis to steatohepatitis, fibrosis, and cirrhosis[1]. It has placed a heavy economic burden on health care systems globally[1]. With changes of lifestyles, the prevalence of fatty liver in Asia area grows sharply in recent years, with the mean prevalence in China reaching $15 \%$ in 2009[2]. Thus, it is important to seek related risk factors of fatty liver disease and effective strategies to prevent it.

Cooking is an essential part of daily life. Chinese-style cooking including stir-frying and deep-frying which need preheated about $25-100 \mathrm{ml}$ of cooking oil to approximately $280^{\circ} \mathrm{C}$ and produce large quantities of cooking oil fume. [3]Cooking oil fume contains lots of carcinogens, such as polycyclic aromatic 
hydrocarbons $(\mathrm{PAH})$, fine particulate matter (PM), etc. [4, 5]lt is reported that the annual emission rate of total PAH was $2038 \mathrm{~kg}$ /year in Chinese restaurants, which was approximately 8-fold higher than that at restaurants of western. [6]Another study reported that the proportion of PM2.5 emissions from cooking fuels was about $12 \%$ of total global PM2.5 emissions.[7] Several epidemiologic studies have related cooking oil fume to lung cancer and cardiovascular disease.[8, 9] Recently, Jian etc. found that environmental exposure to cooking oil fume is also associated with diabetes.[10] However, few studies has analyzed the association between cooking oil fume and fatty liver although Ames test and the SOS chromotest have found that cooking oil fume contains genotoxicity which related to fatty deposition[11, 12].

Therefore, the present study is conducted to investigate whether exposure to cooking oil fume is related to incident and severity of fatty liver disease.

\section{Methods}

\subsection{Participants}

We performed a cross-sectional study base on Ningbo database of the Cancer Screening Program in Urban China (CanSPUC)[13]. CanSPUC is a national ongoing national cancer screening program which was initiated in October 2012. After obtaining signed written informed consent, all the eligible participants were interviewed face-to-face by trained staffs to collect information about their exposure to risk factors. Cancer screening program in Ningbo, Zhejiang began at 2013 and a total of 55959 participants (male= 24961 , female $=30998)$ aged $40-75$ years were included during 2013-2017. Participants with incomplete data on cooking oil fume $(n=1)$, fat liver disease $(n=899)$, menopausal status $(n=1)$ were excluded. Finally, 55058 participants $($ male $=24551$, female $=30507$ ) were included in our analyses.

\subsection{Questionnaires}

Fatty liver disease, environmental exposure to cooking oil fume, gender, age, menopausal status, weight, height, waist, education, active and passive smoke, alcohol drinking, dietary fat intake, physical activity, and metabolic disease (hypertension, hyperlipemia and type 2 diabetes) were collected through face-toface interview. Participants who had self-reported fatty liver disease were further grouped as light fatty liver, moderate fatty liver and heavy fatty liver by asking "how severer is the disease?". Cooking oil fume exposure was leveled as smokeless, light, moderate and heavy. Body mass index (BMI) is calculated by dividing body weight in kilograms by the square of height in meters. Education was classified as illiteracy, primary or middle school, high school and college or above. Information on active smoking was obtained by asking current and lifetime smoking habits and classed as smoker (current or former smoker) or nonsmoker. Passive smoking was defined by asking "Are there smokers living in the participants' family or at their workplace". Alcohol drinking was classified as never, regular and quit. Dietary fat intake was leveled as high fat diet, moderate fat diet and low-fat diet. Regular exercise was defined according to whether participants do exercises at least 3 times a week and 30 minutes every time. 


\subsection{Statistical analysis}

The characteristics of the participants were summarized as mean \pm standard deviation (SD) for continuous variables and as frequency (percentages) for the categorical variables. Analyses of variance (ANOVA) and Bonferroni test were used to compare continuous variables, and chi-squared tests were used to compare categorical variables across different cooking oil fume exposure groups.

Multiple logistic regression analyses were conducted to investigate the association between cooking oil fume exposure and fatty liver risk after adjusting for gender, age, BMI, waist, education, active and passive smoke, alcohol drinking, dietary fat intake, regular exercise and metabolic disease.

Interactive analysis was used to evaluate the interaction between cooking oil fume exposure and gender. And then participants were divided into two groups as significant interaction was observed. Multiple logistic regression models were respectively rerun in males and females, and models in females were additionally adjusted for menopausal status. Furthermore, multiple ordinal logistic regression analyses were used to examine the association between cooking oil fume exposure and the severity of fatty liver disease with same confounders adjusted in the multiple logistic regression analyses ( $P$ value of proportional odds assumption $<0.001$ ). A value of $p<0.05$ (two sided) was considered statistically significant unless otherwise indicated. Stata version 13 was used for data analyses (Stata Corporation, College Station, TX).

\section{Results}

The characteristics of participants are shown in Table 1. Participants who were exposed to heavier cooking oil fume were more likely to develop fatty liver disease (all $p<0.001)$. Significant differences were found in waist, education, alcohol use, active and passive smoke, dietary fat intake, physical activity (all p < 001). Participants in the heavy cooking fume exposure group had the highest risk of metabolic disease (hypertension, dyslipidemia and type 2 diabetes, all $p<0.05$ ). There were no significant differences in age, menopausal status and waist across cooking oil fume exposure groups $(p>0.05)$. 
Table 1

Descriptive characteristics of study participants.

\begin{tabular}{|c|c|c|c|c|c|}
\hline \multirow{3}{*}{$\begin{array}{l}\text { Variables } \\
\mathrm{N}(\%) \text { or mean (SD) }\end{array}$} & \multicolumn{4}{|c|}{ Cooking oil fumes exposure } & \multirow[t]{3}{*}{$P$ value } \\
\hline & Smokeless & Light & Moderate & Heavy & \\
\hline & $(n=10643)$ & $(n=39895)$ & $(n=4175)$ & $(n=345)$ & \\
\hline Age, y & $57.13 \pm 7.71$ & $57.02 \pm 7.97$ & $57.23 \pm 7.80$ & $56.48 \pm 8.13$ & 0.124 \\
\hline Male ${ }^{b, d}$ & $\begin{array}{l}4805 \\
(45.15)\end{array}$ & $\begin{array}{l}17852 \\
(44.75)\end{array}$ & $\begin{array}{l}1740 \\
(41.68)\end{array}$ & $154(44.64)$ & 0.001 \\
\hline $\mathrm{BMI}, \mathrm{kg} / \mathrm{m}^{2}$ & $23.75 \pm 5.54$ & $23.67 \pm 6.35$ & $23.81 \pm 4.95$ & $23.69 \pm 3.00$ & 0.348 \\
\hline Waist, $\mathrm{cm}^{\mathrm{a}, \mathrm{d}}$ & $81.92 \pm 9.80$ & $80.90 \pm 9.71$ & $81.73 \pm 9.97$ & $82.03 \pm 9.73$ & $<0.001$ \\
\hline Education ${ }^{a, d}$ & & & & & $<0.001$ \\
\hline Illiteracy & 340 (3.19) & $1341(3.36)$ & $180(4.31)$ & $19(5.51)$ & \\
\hline Primary or secondary & $\begin{array}{l}7069 \\
(66.42)\end{array}$ & $\begin{array}{l}23839 \\
(59.75)\end{array}$ & $\begin{array}{l}2683 \\
(64.26)\end{array}$ & $205(59.42)$ & \\
\hline High School & $\begin{array}{l}2826 \\
(26.55)\end{array}$ & $\begin{array}{l}12456 \\
(31.22)\end{array}$ & $\begin{array}{l}1123 \\
(26.90)\end{array}$ & $99(28.70)$ & \\
\hline College or above & $408(3.83)$ & $2259(5.66)$ & $189(4.53)$ & $22(6.38)$ & \\
\hline Alcohol user $a, b, c, d, e, f$ & $\begin{array}{l}2646 \\
(24.86)\end{array}$ & $8418(21.10)$ & $\begin{array}{l}1366 \\
(32.72)\end{array}$ & $139(40.29)$ & $<0.001$ \\
\hline Smoker $a, b, c, d, e, f$ & $\begin{array}{l}2879 \\
(27.05)\end{array}$ & $8964(22.47)$ & $\begin{array}{l}1403 \\
(33.60)\end{array}$ & $146(42.32)$ & $<0.001$ \\
\hline Passive smoker $a, b, c, d, e, f$ & $\begin{array}{l}3215 \\
(30.21)\end{array}$ & $\begin{array}{l}12994 \\
(32.57)\end{array}$ & $\begin{array}{l}2941 \\
(70.44)\end{array}$ & $310(89.86)$ & $<0.001$ \\
\hline Fat intake $b, c, d, e, f$ & & & & & $<0.001$ \\
\hline Low & $\begin{array}{l}1239 \\
(11.64)\end{array}$ & $4990(12.51)$ & $271(6.49)$ & $18(5.22)$ & \\
\hline Middle & $\begin{array}{l}8678 \\
(81.54)\end{array}$ & $\begin{array}{l}31400 \\
(78.71)\end{array}$ & $\begin{array}{l}2136 \\
(51.16)\end{array}$ & 131 (37.97) & \\
\hline High & $726(6.82)$ & 3505 (8.79) & $\begin{array}{l}1768 \\
(42.35)\end{array}$ & $196(56.81)$ & \\
\hline 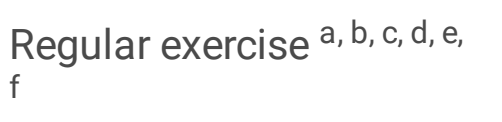 & $\begin{array}{l}5572 \\
(52.35)\end{array}$ & $\begin{array}{l}23023 \\
(57.71)\end{array}$ & $1262(3023)$ & $56(16.23)$ & $<0.001$ \\
\hline Hypertension a, b, c, d, e, f & $\begin{array}{l}3214 \\
(30.20)\end{array}$ & $\begin{array}{l}11188 \\
(28.04)\end{array}$ & $\begin{array}{l}1416 \\
(33.92)\end{array}$ & $144(41.74)$ & $<0.001$ \\
\hline
\end{tabular}




\begin{tabular}{|c|c|c|c|c|c|}
\hline \multirow{2}{*}{$\begin{array}{l}\text { Variables } \\
N(\%) \text { or mean (SD) }\end{array}$} & \multicolumn{4}{|c|}{ Cooking oil fumes exposure } & \multirow[t]{3}{*}{$P$ value } \\
\hline & Smokeless & Light & Moderate & Heavy & \\
\hline & $(n=10643)$ & $(n=39895)$ & $(n=4175)$ & $(n=345)$ & \\
\hline Dyslipidemia ${ }^{b}, c, d, e, f$ & $\begin{array}{l}1712 \\
(16.09)\end{array}$ & $6847(17.16)$ & $\begin{array}{l}1149 \\
(27.52)\end{array}$ & $146(42.32)$ & $<0.001$ \\
\hline Diabetes ${ }^{a}, c, d, e, f$ & $1014(9.53)$ & $3282(8.23)$ & $436(10.44)$ & $53(15.36)$ & $<0.001$ \\
\hline \multicolumn{5}{|c|}{ Fatty liver disease ${ }^{a, b, c, d, e, f}$} & $<0.001$ \\
\hline Normal & $\begin{array}{l}9708 \\
(91.21)\end{array}$ & $\begin{array}{l}35699 \\
(89.48)\end{array}$ & $\begin{array}{l}3195 \\
(76.53)\end{array}$ & $202(58.55)$ & \\
\hline Light & $650(6.11)$ & $3017(7.56)$ & $501(12.00)$ & $42(12.17)$ & \\
\hline Moderate & $239(2.25)$ & $967(2.42)$ & $372(8.91)$ & $63(18.26)$ & \\
\hline Heavy & $56(0.43)$ & $212(0.53)$ & $107(2.56)$ & $38(11.01)$ & \\
\hline \multicolumn{6}{|c|}{ Abbreviations: BMI, body mass index; SD, standard deviation. } \\
\hline \multicolumn{6}{|c|}{ Analysis of variance (ANOVA) for continuous variables and chi ${ }^{2}$ test for categorical. } \\
\hline \multicolumn{6}{|c|}{$\begin{array}{l}\text { a } p<0.05 \text { Significant difference between participants in none and low cooking oil fumes exposure } \\
\text { group. }\end{array}$} \\
\hline \multicolumn{6}{|c|}{$\begin{array}{l}\text { b } \mathrm{p}<0.05 \text { Significant difference between participants in none and middle cooking oil fumes exposure } \\
\text { group. }\end{array}$} \\
\hline \multicolumn{6}{|c|}{$\begin{array}{l}\text { c p }<0.05 \text { Significant difference between participants in none and high cooking oil fumes exposure } \\
\text { group. }\end{array}$} \\
\hline \multicolumn{6}{|c|}{$\begin{array}{l}\mathrm{d} p<0.05 \text { Significant difference between participants in low and middle cooking oil fumes exposure } \\
\text { group. }\end{array}$} \\
\hline \multicolumn{6}{|c|}{$\begin{array}{l}\text { e } p<0.05 \text { Significant difference between participants in low and high cooking oil fumes exposure } \\
\text { group. }\end{array}$} \\
\hline \multicolumn{6}{|c|}{$\begin{array}{l}f \mathrm{p}<0.05 \text { Significant difference between participants in middle and high cooking oil fumes exposure } \\
\text { group. }\end{array}$} \\
\hline
\end{tabular}

Associations between cooking oil fume exposure and prevalence of fatty liver disease are shown in Table 2. Compared with participants in smokeless group, the adjusted ORs for fatty liver disease among participants in light, moderate and heavy cooking oil fume exposure groups were $1.24(95 \% \mathrm{Cl} 1.15-1.35$, $\mathrm{P}<0.001), 1.64$ (95\% Cl 1.46-1.84, $\mathrm{P}<0.001), 2.60$ (95\% Cl 1.99-3.39, $\mathrm{P}<0.001)$, respectively. Participants with heavier cooking oil fume exposure tended to have higher risk of fatty liver disease $(P<0.001)$. 
Table 2

The association between cooking oil fumes exposure and fatty liver disease

\section{Cooking oil fumes exposure}

Smokeless

Light

Moderate

Heavy

P for trend
OR $(95 \% \mathrm{Cl})$

$P$ value

1.00

$1.24(1.15,1.35)$

$1.64(1.46,1.84)$

$2.60(1.99,3.39)$

$<0.001$

Models were adjusted for age, gender, body mass index, waist, education level, smoking, passive smoker, alcohol assumption, regular exercise, fat intake habits, hypertension, dyslipidemia and diabetes.

In the interactive analysis, we observed significant interaction between cooking oil fume exposure and gender on the risk of fatty liver disease (OR for interaction $=0.858, \mathrm{P}$ for interaction $=0.001$ ). Compared with males in the smokeless group, females in the heavy cooking oil fume exposure group had the highest risk of fatty liver disease and severest disease extent among all participants $(O R=4.36, P<0.001$, Figure a.; $\mathrm{OR}=6.08, \mathrm{P}<0.001$, Figure b.).

Thus, models were rerun with participants being divided into two groups according to gender (Table 3 ). Compared to participants in the smokeless group, males and females in light, moderate and heavy cooking oil fume exposure groups all had significantly higher risk of fatty liver disease, while participants with heavier cooking oil fume exposure tended to have higher risk of fatty liver disease (all $P<0.001$ ).

Table 3

The association between cooking oil fumes exposure and fatty liver disease by gender

\section{Cooking oil fumes exposure}

Male

OR $(95 \% \mathrm{Cl})$

1.00

$1.22(1.08,1.37)$ ***

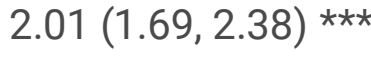

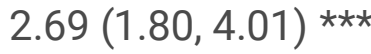

$<0.001$
Female

OR (95\%Cl)

1.00

$1.27(1.14,1.42)$ ***

$1.41(1.20,1.65)$ ***

Heavy

P for trend

Models were adjusted for age, gender, body mass index, waist, education level, smoking, passive smoker, alcohol assumption, regular exercise, fat intake habits, hypertension, dyslipidemia and diabetes. Females were additionally adjusted for menopausal status.

$\star * \star \mathrm{P}<0.001$ 
Associations between cooking oil fume exposure and severity of fatty liver disease were further analyzed in males and females, respectively (Table 4). Compared to participants in the smokeless group, males and females in light, moderate and heavy cooking oil fume exposure groups all had significantly higher risk of severer fatty liver disease (all $P<0.001$ ). Besides, participants with heavier cooking oil fume exposure tended to have higher risk of severer fatty liver disease.

Table 4

The association between cooking oil fumes exposure and severity of fatty liver disease by gender.

\begin{tabular}{|c|c|c|}
\hline \multirow[t]{2}{*}{ Cooking oil fumes exposure } & Male & Female \\
\hline & OR $(95 \% \mathrm{Cl})$ & OR $(95 \% \mathrm{Cl})$ \\
\hline Smokeless & 1.00 & 1.00 \\
\hline Light & 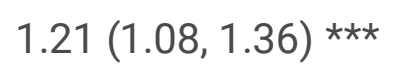 & $1.24(1.11,1.38) * \star \star$ \\
\hline Moderate & 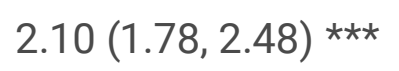 & $1.46(1.25,1.70) * \star *$ \\
\hline Heavy & 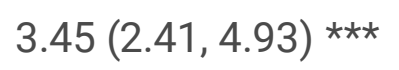 & $3.37(2.41,4.71) * \star \star$ \\
\hline$P$ for trend & $<0.001$ & $<0.001$ \\
\hline
\end{tabular}

Models were adjusted for age, gender, body mass index, waist, education level, smoking, passive smoker, alcohol assumption, regular exercise, fat intake habits, hypertension, dyslipidemia and diabetes. Females were additionally adjusted for menopausal status.

$\star * \star \mathrm{P}<0.001$

Figure. a. Combined effect of cooking oil fumes exposure and gender on risk of fatty liver disease (FLD).

b. Combined effect of cooking oil fumes exposure and gender on severity of FLD.

Odds ratios were all adjusted for age, gender, body mass index, waist, education level, smoking, passive smoker, alcohol assumption, regular exercise, fat intake habits, hypertension, dyslipidemia and diabetes.

All $\mathrm{P}<0.001$.

\section{Discussion}

In the present study, we found a positive association between cooking oil fume exposure and fatty liver disease after adjusting for various potential confounders in Chinese adults. Participants who exposure to heavier cooking oil fume tended to have higher risk of fatty liver disease and severer disease extent. In addition, we observed significant interaction between cooking oil fume exposure and gender on the risk of fatty liver disease. Female with heavy cooking oil fume exposure was associated with the highest observed odds ratio of fatty liver disease and severer disease extent. 
Cooking fume exposure has been found to be related with many chronic diseases such as lung cancer, cardiovascular disease and diabetes.[8-10] Previous animal studies also found that carcinogens contained in cigarette smoke, which can also be found in cooking oil fume, might accelerate fat deposition in liver.[14] However, clinical data on the association between environmental exposure to cooking oil fume and fatty liver disease is limited. In the present study, we firstly found that cooking oil fume is significantly associated with fatty liver disease and severer disease extent even after adjusting for possible confounders. In addition, participants with heavier cooking oil fume exposure tended to have higher odds ratios of fatty liver disease and severer disease extent, suggesting a dose-response relationship between cooking oil fume exposure and fatty liver. However, the mechanism underlying the association is still unclear. There is plenty of evidences showed that exposure to environmental PAHs induced oxidative DNA damage and elevated systemic inflammatory marker (C-reactive protein) in general population. $[15,16]$ Both DNA damage and inflammatory response contribute to decomposition of fatty acid which is involved in the development of fatty liver.[17, 18] Similarly, PM, another important component of cooking oil fume, related to fat redistribution and metabolism as well.[19, 20] Additionally, Tan et al found that PM that reached the liver could induce Kupffer cell cytokine secretion, which then trigger inflammation and hepatic stellate cell collagen synthesis.[21]

In the interaction analyses, we found a synergistic effect between heavy cooking oil fume exposure and female sex on fatty liver disease and severer disease extent. Female with heavy cooking oil fume exposure was associated with highest risk for fatty liver disease and severest disease extent, suggesting female were more likely to be affected by cooking oil fume than male. Consistent with our observation, previous studies reported that female were more susceptible to environmental pollutants in relation to oxidative stress and diabetes than male.[22, 23] A possible explanation is the higher activity of CYP1A1 which can produce higher levels of DNA adducts and lower DNA repair capacity in female than male.[24] In addition, body fat mass and abdominal fat mass have been documented to be associated with increased systemic inflammation and reduced anti-inflammation function and might also have modifying effects on the cross-sectional association between environmental pollutants and metabolic disease.[25] Thus, the different associations between cooking oil fumes and fatty liver among males and females might partly because that females have higher body fat mass and abdominal fat mass than male.[26] However, in the stratified analysis, the associations between cooking oil fume exposure and fatty live disease were found in both males and females. The results indicated that the positive association between cooking oil fume exposure and fatty liver disease should be noted in both males and females.

The present study has several strengths. Our study firstly related cooking oil fume to fatty liver disease and found a dose-response relationship between cooking oil fume exposure and fatty liver. Secondly, the sample size was relatively large, making the statistical significance being robust. Thirdly, a series of important confounders, such as dietary fat intake, social economic factors and metabolic diseases, were taken into consideration in the analysis. Lastly, collapsing environmental exposure of cooking oil fume, severity of fatty liver into four categories separately enabled us to have a better understanding on the associations between cooking oil fume and fatty liver. 
Conversely, limitations should also be noted. First, because of the cross-sectional design, a causal relationship between cooking oil fume and fatty liver may not be inferred. Second, the measurement of cooking oil fume exposure and fatty liver were based on self-report only, which may lead to recall bias and misclassification. Prospective and longitudinal studies should be made in the future with more accurate information on cooking oil fume exposure and fatty liver. Third, participants with nonalcoholic fatty liver disease cannot be distinguished from alcoholic fatty liver disease in our study. However, a sensitive analyze included only nondrinker observed similar results (table S1, table S2).

\section{Conclusion}

In conclusion, our study found that there may be a dose-dependent association between cooking oil fume exposure and fatty liver disease. In addition, heavy cooking oil fume exposure might have a synergistic effect with female sex on fatty liver disease. These findings add to the current understanding regarding fatty liver prevention. Future studies should be conducted to explore the underlying mechanism of this association and whether effective cooking oil fume control means like a fume extractor in home kitchen can reduce the risk of fatty liver.

\section{Declarations}

\section{Ethics approval and consent to participate}

This study was approved by the Ethics Committee of Cancer Hospital Chinese Academy of Medical Science.

\section{Consent for publication}

Not applicable

\section{Availability of data and materials}

The data that support the findings of this study are available from Cancer Hospital Chinese Academy of Medical Science but restrictions apply to the availability of these data, which were used under license for the current study, and so are not publicly available. Data are however available from the authors upon reasonable request and with permission of Cancer Hospital Chinese Academy of Medical Science.

\section{Competing interests}

The authors declare that they have no competing interests 


\section{Funding}

This study was supported by the Natural Science Foundation of Zhejiang Province (LY15H160046) and Ningbo Science and Technology Innovation Team (2011B82016)

\section{Contributors}

$\mathrm{JL}, \mathrm{SZ}$ and TC designed the study. JL and SN analyzed the data and drafted the manuscript. JL, SN, QS, $Z X, J K, X S, Y G, H Z$ and SL contributed to the discussion and the interpretation of data and results and revised the manuscript. SZ has primary responsibility for the final content. All the authors have read and approved the final manuscript.

\section{Acknowledgements}

We sincerely thank National Cancer center of China. We would also like to thank the staff and physicians of all the members of Cancer Screening Program in Ningbo, China for providing support in the filed surveys. Lastly, we are grateful to participants for attending this study.

\section{References}

1. Sweet PH, Khoo T, Nguyen S. Nonalcoholic Fatty Liver Disease. Primary care. 2017;44(4):599-607.

2. Fan JG, Farrell GC. Epidemiology of non-alcoholic fatty liver disease in China. Journal of hepatology. 2009;50(1):204-10.

3. Tung YH, Ko JL, Liang YF, Yin L, Pu Y, Lin P. Cooking oil fume-induced cytokine expression and oxidative stress in human lung epithelial cells. Environmental research. 2001;87(1):47-54.

4. Singh A, Chandrasekharan Nair K, Kamal R, Bihari V, Gupta MK, Mudiam MK, Satyanarayana GN, Raj A, Haq I, Shukla NK, et al. Assessing hazardous risks of indoor airborne polycyclic aromatic hydrocarbons in the kitchen and its association with lung functions and urinary PAH metabolites in kitchen workers. Clin Chim Acta. 2016;452:204-13.

5. Sjaastad AK, Jorgensen RB, Svendsen K. Exposure to polycyclic aromatic hydrocarbons (PAHs), mutagenic aldehydes and particulate matter during pan frying of beefsteak. Occup Environ Med. 2010;67(4):228-32.

6. Li CT, Lin YC, Lee WJ, Tsai PJ. Emission of polycyclic aromatic hydrocarbons and their carcinogenic potencies from cooking sources to the urban atmosphere. Environmental health perspectives. 2003;111(4):483-7.

7. Chafe ZA, Brauer M, Klimont Z, Van Dingenen R, Mehta S, Rao S, Riahi K, Dentener F, Smith KR. Household cooking with solid fuels contributes to ambient PM2.5 air pollution and the burden of disease. Environmental health perspectives. 2014;122(12):1314-20. 
8. Lin H, Tao J, Du Y, Liu T, Qian Z, Tian L, Di Q, Rutherford S, Guo L, Zeng W, et al. Particle size and chemical constituents of ambient particulate pollution associated with cardiovascular mortality in Guangzhou, China. Environmental pollution (Barking Essex: 1987). 2016;208(Pt B):758-66.

9. Xia Z, Duan X, Tao S, Qiu W, Liu D, Wang Y, Wei S, Wang B, Jiang Q, Lu B, et al: Pollution level, inhalation exposure and lung cancer risk of ambient atmospheric polycyclic aromatic hydrocarbons (PAHs) in Taiyuan, China. Environmental pollution (Barking, Essex. 1987) 2013, 173:150-156.

10. Hou J, Sun H, Zhou Y, Zhang Y, Yin W, Xu T, Cheng J, Chen W, Yuan J. Environmental exposure to polycyclic aromatic hydrocarbons, kitchen ventilation, fractional exhaled nitric oxide, and risk of diabetes among Chinese females. Indoor air. 2018;28(3):383-93.

11. Chiang TA, Wu PF, Ko YC. Identification of carcinogens in cooking oil fumes. Environmental research. 1999;81(1):18-22.

12. Chiang TA, Wu PF, Wang LF, Lee $H$, Lee $\mathrm{CH}$, Ko YC. Mutagenicity and polycyclic aromatic hydrocarbon content of fumes from heated cooking oils produced in Taiwan. Mutat Res. 1997;381(2):157-61.

13. Chen H, Li N, Ren J, Feng X, Lyu Z, Wei L, Li X, Guo L, Zheng Z, Zou S, et al: Participation and yield of a population-based colorectal cancer screening programme in China. Gut 2018.

14. Azzalini L, Ferrer E, Ramalho LN, Moreno M, Dominguez M, Colmenero J, Peinado VI, Barbera JA, Arroyo $\mathrm{V}$, Gines $\mathrm{P}$, et al. Cigarette smoking exacerbates nonalcoholic fatty liver disease in obese rats. Hepatology. 2010;51(5):1567-76.

15. Kuang D, Zhang W, Deng Q, Zhang X, Huang K, Guan L, Hu D, Wu T, Guo H. Dose-response relationships of polycyclic aromatic hydrocarbons exposure and oxidative damage to DNA and lipid in coke oven workers. Environ Sci Technol. 2013;47(13):7446-56.

16. Dung $\mathrm{CH}$, Wu SC, Yen GC. Genotoxicity and oxidative stress of the mutagenic compounds formed in fumes of heated soybean oil, sunflower oil and lard. Toxicology in vitro: an international journal published in association with BIBRA. 2006;20(4):439-47.

17. Akazawa Y, Nakashima R, Matsuda K, Okamaoto K, Hirano R, Kawasaki H, Miuma S, Miyaaki H, Malhi $\mathrm{H}$, Abiru S, et al: Detection of DNA damage response in nonalcoholic fatty liver disease via p53binding protein 1 nuclear expression. Modern pathology: an official journal of the United States and Canadian Academy of Pathology, Inc 2019.

18. Prussick RB, Miele L. Nonalcoholic fatty liver disease in patients with psoriasis: a consequence of systemic inflammatory burden? Br J Dermatol. 2018;179(1):16-29.

19. Lawal AO. Air particulate matter induced oxidative stress and inflammation in cardiovascular disease and atherosclerosis: The role of Nrf2 and AhR-mediated pathways. Toxicology letters. 2017;270:8895.

20. Rajkumar S, Young BN, Clark ML, Benka-Coker ML, Bachand AM, Brook RD, Nelson TL, Volckens J, Reynolds SJ, L'Orange $C$, et al. Household air pollution from biomass-burning cookstoves and metabolic syndrome, blood lipid concentrations, and waist circumference in Honduran women: A cross-sectional study. Environmental research. 2019;170:46-55. 
21. Tan HH, Fiel MI, Sun Q, Guo J, Gordon RE, Chen LC, Friedman SL, Odin JA, Allina J. Kupffer cell activation by ambient air particulate matter exposure may exacerbate non-alcoholic fatty liver disease. J Immunotoxicol. 2009;6(4):266-75.

22. Guo H, Huang K, Zhang X, Zhang W, Guan L, Kuang D, Deng Q, Deng H, Zhang X, He M, et al. Women are more susceptible than men to oxidative stress and chromosome damage caused by polycyclic aromatic hydrocarbons exposure. Environ Mol Mutagen. 2014;55(6):472-81.

23. Hansen AB, Ravnskjaer L, Loft S, Andersen KK, Brauner EV, Baastrup R, Yao C, Ketzel M, Becker T, Brandt $\mathrm{J}$, et al. Long-term exposure to fine particulate matter and incidence of diabetes in the Danish Nurse Cohort. Environment international. 2016;91:243-50.

24. Uppstad H, Osnes GH, Cole KJ, Phillips DH, Haugen A, Mollerup S. Sex differences in susceptibility to PAHs is an intrinsic property of human lung adenocarcinoma cells. Lung cancer (Amsterdam Netherlands). 2011;71(3):264-70.

25. Kim HJ, Kwon H, Jeong SM, Hwang SE, Park JH. Effects of abdominal visceral fat compared with those of subcutaneous fat on the association between PM10 and hypertension in Korean men: A cross-sectional study. Scientific reports. 2019;9(1):5951.

26. Yang M, Lin J, Ma X, Zhu C, Wei C, Wang L, Jiao J, Zhu S. Truncal and leg fat associations with metabolic risk factors among Chinese adults. Asia Pac J Clin Nutr. 2016;25(4):798-809.

\section{Figures}
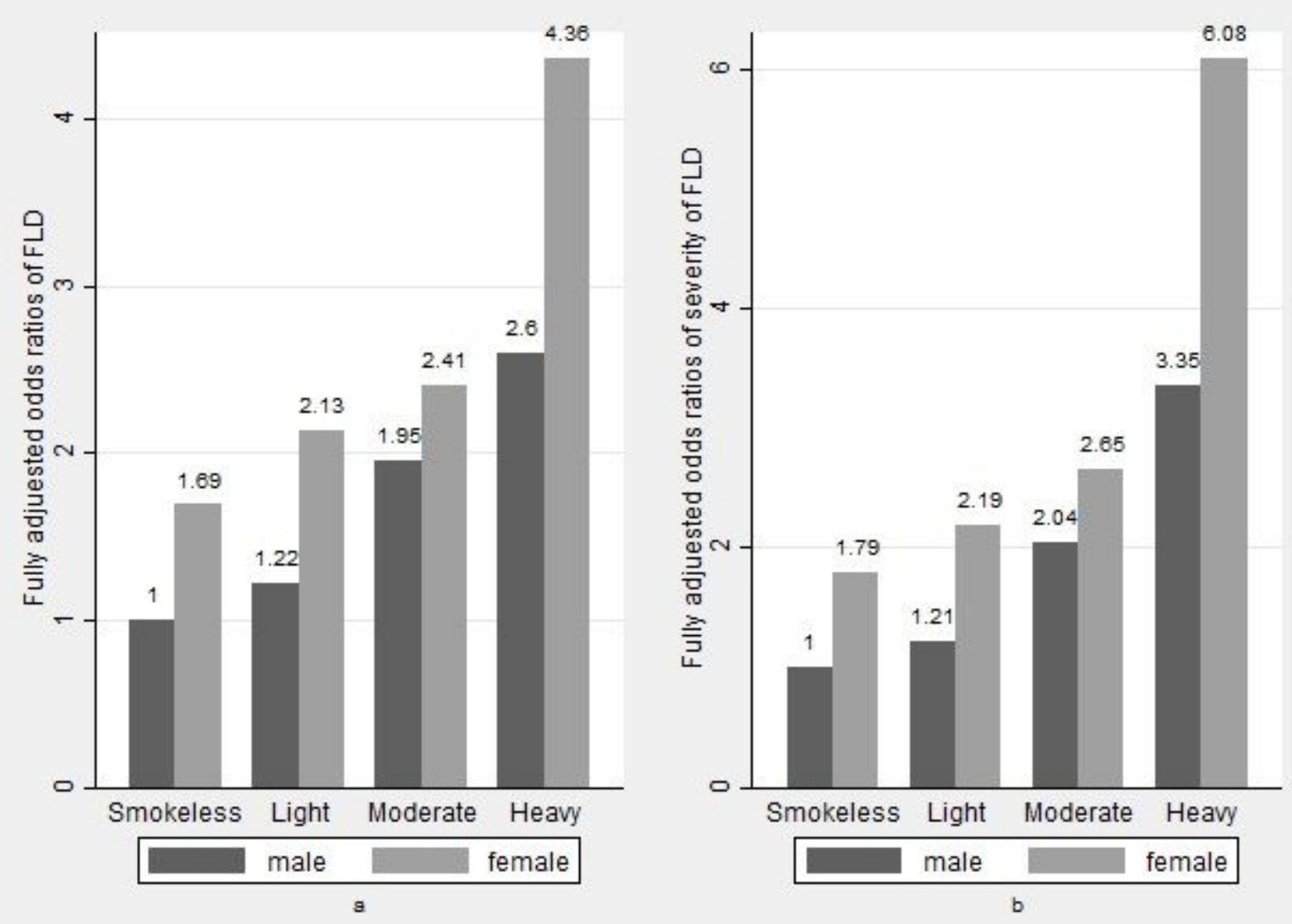


\section{Figure 1}

Fully adjusted odds ratios of FLD Fully adjusted odds ratios of severity of FLD

\section{Supplementary Files}

This is a list of supplementary files associated with this preprint. Click to download.

- supplementarymaterial.docx 